\title{
Developing a questionnaire to assess Iranian nurses' knowledge of and attitude to Middle East respiratory syndrome
}

\author{
Masoomeh Abdollahi, ${ }^{1}$ Akram Ghahramanian, ${ }^{1,3}$ Shahla Shahbazi, ${ }^{1}$ Farshid Rezaei, ${ }^{2}$ Behroz Naghili ${ }^{3}$ and Mohammad Asghari-Jafarabadi ${ }^{4}$
}

${ }^{1}$ Department of Medical Surgical Nursing, Faculty of Nursing and Midwifery, Tabriz University of Medical Sciences, Tabriz, Islamic Republic of Iran (Correspondence to: Akram Ghahramanian: ghahramaniana@gmail.com). ${ }^{2}$ Iranian Centre for Communicable Disease Control, Tehran, Islamic Republic of Iran. ${ }^{3}$ Infectious and Tropical Diseases Research Centre, Tabriz University of Medical Sciences, Tabriz, Islamic Republic of Iran. ${ }^{4}$ Road Traffic Injury Research Centre, Tabriz University of Medical Sciences, Tabriz, Islamic Republic of Iran.

\begin{abstract}
Background: With the emergence of Middle East respiratory syndrome (MERS), health care preparedness has received increasing attention, which requires valid tools to assess the knowledge and attitude of health workers, such as nurses, with regard to this disease.
\end{abstract}

Aims: This study aimed to develop and evaluate a knowledge and attitudes questionnaire on MERS coronavirus for Iranian nurses.

Methods: A questionnaire was developed based on international and national guidelines and a literature review. Ten nurses were recruited to assess face validity and 11 experts reviewed the instrument to determine the content validity ratio and index. Exploratory factor analysis was then done with a random sample of 155 nurses in Tabriz city, Islamic Republic of Iran.

Results: Following determination of face and content validity, 78 items (61 knowledge and 17 attitude) were retained in the final version of the questionnaire. The knowledge scale had an average content validity index of 0.80 and the attitude scale a value of 0.91. In the exploratory factor analysis, five dimensions with eigenvalues $>1$ and loading level $\geq 0.4$ were extracted for the knowledge scale (46 items) and two for the attitude scale ( 16 items). The Kuder-Richardson 21 coefficient and intraclass correlation coefficient for the knowledge scale were 0.94 and 0.91 respectively. In the attitude scale, the Cronbach alpha coefficient and intraclass correlation coefficients were 0.82 and 0.89 respectively.

Conclusions: The scale developed in this study is reliable and stable and a suitable instrument for evaluating the knowledge and attitude of nurses about MERS-CoV.

Keywords: Middle East respiratory syndrome, surveys and questionnaires, knowledge, attitude, health care providers, Islamic Republic of Iran

Citation: Abdollahi M; Ghahramanian A; Shahbazi S, Rezaei F; Naghili B; Asghari-Jafarabadi M. Developing a questionnaire to assess the knowledge and attitude of Iranian nurses to Middle East respiratory syndrome. East Mediterr Health J. 2020;26(5):506-516. https://doi.org/10.26719/emhj.19.065

Received: 07/03/18; accepted: 24/05/18

Copyright (c) World Health Organization (WHO) 2020. Open Access. Some rights reserved. This work is available under the CC BY-NC-SA 3.0 IGO license (https://creativecommons.org/licenses/by-nc-sa/3.o/igo).

\section{Introduction}

Middle East respiratory syndrome (MERS) is a respiratory disease caused by a coronavirus (MERS-CoV). The disease was first reported in Saudi Arabia in 2012. Coronaviruses are a large family of viruses that can cause various diseases from colds to severe acute respiratory syndrome (SARS) (1). Since it was first reported in 2012 to 27 April 2017, 1952 laboratory-confirmed cases of infection with MERS-CoV have been reported to the World Health Organization (WHO), including at least 693 related deaths (2). Cases of MERS have been reported in 27 countries in and around the Arabian peninsula, including the Islamic Republic of Iran, and more distant countries - Germany, United Kingdom, United States of America, Korea, Turkey, Egypt and Malaysia - as a result of travel to affected countries (3). In the Islamic Republic of Iran, a cluster of the disease was reported in five people in 2014 (4) and another case was reported in 2015 (5).

The disease is transmitted through direct or indirect contact with infected camel secretions and/or droplets of people with the virus. Symptoms of MERS resemble those of influenza-like illness with fever, cough and severe dyspnoea (6). No vaccines and treatments are available for the disease. The highest prevalence of MERS is reported from health centres (1,7). In Korea (8) and Jeddah, Saudi Arabia (9), for example, the disease spread through contact with affected people in hospital. Disease transmission through common interpersonal contact between people is unknown in the community.

Since most reported cases of MERS are from the Middle East, and Iranians frequently travel to neighbouring Arab countries, including Saudi Arabia (10), health care personnel in the Islamic Republic of Iran need to have an understanding of the disease and the infection control measures that should be used (11). At the same time, health care providers may have concerns about occupational safety and disease transmission to friends and family while providing health services to patients with MERS. To manage coronavirus diseases, it is therefore essential to evaluate the knowledge and 
attitudes of health care providers about the disease in order to determine the extent to which they are prepared for the necessary measures for this disease and to provide in-service training where required (12).

Given that the disease has emerged quite recently, few studies have been conducted and a limited number of instruments developed to assess the knowledge and attitudes of health care providers about MERS-CoV. Despite the importance of a valid and reliable instrument to evaluate health care workers knowledge and attitudes about the virus and the disease, a review of the literature suggests inadequacies in the design and psychometry of existing tools $(10,13-17)$.

Researchers in Saudi Arabia used a questionnaire to examine the knowledge and attitudes of health care providers about MERS-CoV in 2015 (13), but the results for content validity ratio and content validity index of the items was not reported, nor was the reliability of the questionnaire, even though these measures were done. In another similar study in Saudi Arabia (10), the questionnaire used was evaluated for face and content validity but no results were presented for the content validity ratio and index. The Cronbach alpha for reliability of the questionnaire was given as 0.74 , but it was not clear whether this value applied to the attitude or knowledge scale. In a study in the Republic of Korea on knowledge, preventive behaviour and risk perception of nursing students at the outbreak of MERS-CoV in the country, the authors reported the content validity index and Kuder-Richardson values, but they provided no data on the content validity ratio, face validity and construct validity (14). A study in Turkey on the knowledge, attitude, and practices of Hajj and Umra pilgrims about MERS did not report the validity and reliability of the questionnaire used (15). Similarly, these measures were not reported in a study on the knowledge of physicians about MERS-CoV in Pakistan (16) and another study on the knowledge, attitude and practices of health care providers in Saudi Arabia (17).

Reliable and valid instruments to measure the knowledge and attitude of health care providers about coronaviruses are also lacking in the Islamic Republic of Iran. This study, therefore, aimed to develop and evaluate a knowledge and attitude scale for MERS-CoV.

\section{Methods}

\section{Study design}

A methodological study with cross-sectional data collection was conducted to develop a knowledge and attitude scale for nurses about MERS-CoV and make a psychometric evaluation.

\section{Development of the scale}

Guidelines on MERS were obtained from the websites of WHO, Centers for Disease Control and Prevention (CDC), USA and the Iranian Centre for Communicable Disease Management. The guidelines were analysed for quantitative content and the aspects of MERS that a nurse should be aware of. Scopus, PubMed, ProQuest and Google Scholar, and Iranmedex, Scientific Information Database (SID) and MagIran in the Islamic Republic of Iran were searched for articles and related tools. A combined search method was used in order to incorporate dimensions and attributes not identified previously. Keywords used were: knowledge, attitude, design, psychometry and Middle East respiratory syndrome. In the literature review, the questionnaire designed by Nour and colleagues in 2015 was used to extract knowledge and attitude items after obtaining permission from the developers of the questionnaire (13).

The scale was divided in two sections. The first part contained the knowledge items with six dimensions and 46 items in a triple-choice response scale (true, false and don't know). The dimensions were: nature of the disease (eight items), transmission of the disease (five items), characteristics of people infected by the coronavirus (three items), prevention (three items), actions in dealing with suspected, probable and confirmed cases ( 24 items), and precautionary measures by health care providers (three items). The second part of the scale contained items on attitude including 11 items with a 5-point Likert scale (strongly agree, agree, uncertain, disagree and strongly disagree).

\section{Face and content validity}

The validity of the scale was assessed though face and content validity. Ten nurses working at Tabriz University of Medical Sciences were selected by convenience sampling and were interviewed to get their views on the appearance, simplicity, and understandability of the items. The nurses were also asked to judge the importance of the items for assessing knowledge and attitudes about MERS-CoV using a 5-point Likert scale: 1, unimportant; 2, slightly important; 3, important; 4, very important; and 5, extremely important. For each item, an impact score was calculated by the number nurses who scored the item 4 or 5 in the importance scale multiplied by the mean score of the item's importance. Items with impact scores of less than 1.5 were excluded from the questionnaire (18).

A panel of 11 experts was then selected: four experts in infection control working in selected hospitals in Tabriz, four infectious disease specialists-one each from Imam Reza Hospital in Tabriz, the Centre for Infectious Diseases Control, the Treatment Department of East Azerbaijan Province and the Iranian Centre for Communicable Disease Control-and three researchers and lecturer in emerging diseases at the Faculty of Nursing and Midwifery of Tabriz University of Medical Sciences. After obtaining necessary permission from the Ethics Committee of Tabriz University of Medical Sciences, the experts were sent the revised scale after face validity and invited to undertake content validity assessment. All the 11 experts responded.

To examine the content validity ratio, the panellists were asked to rate the items on the scale as: necessary, useful but not necessary, or not necessary. Then, the content validity ratio for each item was calculated with 
the formula: content validity ratio $=\left(\mathrm{N}_{\mathrm{e}}-\mathrm{N} / 2\right) / \mathrm{N} / 2$, where $\mathrm{N}$ is the number of panellists in the content validity evaluation and $\mathrm{N}_{e}$ is the number of panellists who rated the item as essential (19). Items with a content validity ratio value less than 0.62 (the critical value in the Lawshe table for 11 panellists) were excluded (19).

After excluding items in the content validity assessment, the content validity index of the scale was determined according to the Waltz and Bausell criteria (20). The comments of the 11 experts on the relevance of each item to whatever had to be measured were assessed based on the following responses: not relevant, item needs some revision, relevant but needs minor revision, and very relevant (20). Experts were also asked to comment on the face validity of items in order to correct them accordingly. The content validity index was calculated for each item and as an average for the whole scale (S-CVI/Ave). To calculate the content validity index of each item, the number of panellists who judged the item as very relevant and relevant but needs minor revision was divided by the total number of panellists.

Items with content validity indexes greater than 0.79 were retained in the scale, those with content validity indexes between 0.70 and 0.79 were revised, and those with content validity indexes less than 0.70 were excluded (21). The content validity index values of all the items were averaged to obtain the S-CVI/Ave for the knowledge and attitude scales.

\section{Construct validity}

To determine the construct validity of the scale, 155 nurses were randomly selected from hospitals affiliated with Tabriz University of Medical Sciences (Table 1). The nurses self-completed the knowledge and attitude scales that had been revised after face and content validity between October 2016 and April 2017. Exploratory factor analysis was used, applying the Kaiser-Meyer-Olkin test for sampling adequacy, the Bartlett test of sphericity, principal component analysis, scree plot and varimax rotation with a cut-off point of 0.4 for factor loading to extract the dimensions of the scale or for the simplification of interrelated measures to discover patterns in a set of variables (22).

\section{Reliability assessment}

Internal consistency and stability reliability were used to determine the reliability of the revised scale. In a pilot study with 25 randomly selected nurses working in a research environment, the internal consistency of the knowledge scale was determined using the Kuder-Richardson-21 formula and that of the attitude scale was ascertained by the Cronbach alpha method. In order to determine the stability of both scales, the same 25 nurses completed the scales two weeks later and the intraclass correlation coefficients were calculated for the scores.

\section{Data analysis}

Data were analysed using SPSS, version 21. The Pearson correlation coefficient was calculated and exploratory

\begin{tabular}{lc}
\hline Table 1 Participants' characteristics & Mean (SD) \\
Characteristic & $31.40(6.57)$ \\
Age (years) & $7.28(6.24)$ \\
Years of nursing experience & $4.11(4.11)$ \\
Years in current position & No. (\%) (n = 155) \\
Sex & $137(88.4)$ \\
Female & $18(11.6)$ \\
Male & \\
Degree & $2(1.3)$ \\
Diploma & $145(93.5)$ \\
Bachelor & $8(5.2)$ \\
Masters & \\
Position & $3(1.9)$ \\
Paramedic & $144(92.9)$ \\
Nurse & $4(2.6)$ \\
Head nurse & $4(2.6)$ \\
Supervisor &
\end{tabular}

factor analysis done. $P<0.05$ was considered statistically significant.

\section{Ethical considerations}

This study was approved by the ethics committee of Tabriz University of Medical Sciences (IR.TBZMED. REC.1395.1065). All stages of data collection were carried out with the agreement of the managers of the study hospitals and head nurses. Prior to data collection, the research objectives were explained to participating nurses and their written informed consent was obtained. They were assured of the confidentiality of their answers and that they had the right to withdraw from the study at any time.

\section{Results}

\section{Face and content validity}

Based on the qualitative judgment of the 10 nurses of the completeness of the dimensions of the knowledge scale, an additional dimension was added called "treatment of the disease". For this new dimension, five items were generated based on the Iranian, WHO and CDC guidelines. The content validity of these new items were then evaluated.

In addition, items were added to the following dimensions.

- Nature of the disease: (i) the coronavirus is contagious up to 24 hours after fever and other symptoms have gone.

- Transmission of the disease: (i) disease transmission from asymptomatic patients and/or those in the disease incubation period, (ii) communicability of MERS by injection of a needle infected with patient's secretions and (iii) communicability of MERS from 
deceased patients.

- Actions in dealing with suspected, probable and confirmed cases: (i) cleaning all contaminated surfaces with a diluted (10\%) bleach solution (ii. elimination of MERS-COV by70\% alcohol.

- Precautionary measures by health care providers: (i) use of personal protective equipment by those responsible for the transfer of deceased patients.

After face and content validity, the knowledge scale had seven dimensions with 61 items. S-CVI/Ave was 0.80 .

In the attitude scale, based on the comments of the 11 panellists, an item was excluded (coronavirus infection can be treated at home), 10 items were corrected, and seven items were added to the content validity: dimension 1 , statements $1-5$ and 10 , dimensions 2 , statement 5 (Table 2). This resulted in a 17-item attitude scale in one dimension. S-CVI/Ave was 0.91.

\section{Construct validity}

In the exploratory factor analysis for the items of the attitude questionnaire, the sampling adequacy was examined with the Kaiser-Meyer-Olkin test which gave a result of 0.758 . The Bartlett test was used to determine whether the correlation matrix obtained was significantly different from zero and could be justified based on factor analysis $(P<0.001)$. In exploratory factor analysis us- ing varimax rotation, two components with eigenvalues greater than 1.0 were extracted which explained $45.72 \%$ of the variance. The first component with 11 items accounted for $27.72 \%$ of the variance and was called "fear and threats of MERS-CoV". The second component accounted for $18.0 \%$ of the variance with five items and was called "beliefs about the prevention of MERS-CoV" (Table 2).

To assess the validity of the knowledge scale, the sampling adequacy was examined by the Kaiser-MeyerOlkin test which gave a result of 0.864 and the Bartlett test was significant $(P<0.001)$. In the exploratory factor analysis using varimax rotation, five components with eigenvalues more than 1.0 were extracted which explained $41.23 \%$ of the variance. The first component with nine items accounted for $5.30 \%$ of the variance and was called "nature of the disease" The second component with seven items accounted for $4.63 \%$ of the variance and was called "transmission of the disease". The third component with 20 items accounted for $18.54 \%$ of the variance and was called "actions in dealing with suspected, probable and confirmed cases". The fourth component with five items accounted for $15.5 \%$ of the variance and was called "precautionary measures by health care providers". Finally, the fifth component with five items accounted for $5.15 \%$ of the variance and was called "treatment of the disease" (Table 3).

Table 2 Results of exploratory factor analysis using a rotated component matrix for attitude to Middle East respiratory syndrome coronavirus (MERS-CoV) infection

\begin{tabular}{|c|c|c|}
\hline Dimensions of attitude scale & \multicolumn{2}{|c|}{ Factor load } \\
\hline \multicolumn{3}{|l|}{ Dimension 1: Fear and threats of MERS-CoV (27.72\% of variance ) } \\
\hline $\begin{array}{l}\text { I am afraid of working in places where patients suspected of MERS-CoV infection are } \\
\text { admitted/cared for }\end{array}$ & \multicolumn{2}{|l|}{0.80} \\
\hline I am afraid of caring for a patient with MERS-CoV infection & \multicolumn{2}{|l|}{0.79} \\
\hline $\begin{array}{l}\text { Despite the use of personal protective equipment and observing infection } \\
\text { transmission precautions, the risk of MERS-CoV infection is high among health care } \\
\text { staff }\end{array}$ & \multicolumn{2}{|l|}{0.61} \\
\hline $\begin{array}{l}\text { I think that the equipment and facilities required to protect health care workers from } \\
\text { MERS-CoV have not been sufficiently provided in the care settings }\end{array}$ & \multicolumn{2}{|l|}{0.60} \\
\hline Higher pay should be received when caring for patients with MERS-CoV infection & \multicolumn{2}{|l|}{0.56} \\
\hline I am afraid that a family member of mine may be affected by MERS-CoV infection & \multicolumn{2}{|l|}{0.55} \\
\hline In case of MERS-CoV outbreak, schools and workplaces should be closed & \multicolumn{2}{|l|}{0.51} \\
\hline MERS-CoV is highly transmissible in hospital & \multicolumn{2}{|l|}{0.49} \\
\hline Health education has no effect on the prevention of MERS-CoV infection & \multicolumn{2}{|l|}{0.48} \\
\hline $\begin{array}{l}\text { I think that training on MERS-CoV is effective in protecting me from the disease in } \\
\text { case of likely exposure (Reverse-scored) }\end{array}$ & \multicolumn{2}{|l|}{0.45} \\
\hline Caring for patients with MERS-CoV infection may be a threat to health care personnel & \multicolumn{2}{|l|}{0.40} \\
\hline \multicolumn{3}{|l|}{ Dimension 2: Beliefs about prevention of MERS-CoV disease (18.0\% of variance) } \\
\hline Public health agencies can control Outbreak of MERS & & 0.75 \\
\hline MERS can have a negative effect on the economies of the countries involved & & 0.74 \\
\hline It is important to report suspected cases to health authorities & & 0.72 \\
\hline MERS is preventable & & 0.64 \\
\hline It is imperative to use a surgical mask when working with the patient with MERS & & 0.57 \\
\hline Total amount of explained variance: $45.72 \%$ of variance & & \\
\hline
\end{tabular}




\section{Table 3 Results of exploratory factor analysis using the rotational component matrix for knowledge of Middle East respiratory} syndrome coronavirus (MERS-CoV) infection

\begin{tabular}{ll}
\hline Dimensions of knowledge scale & \\
Dimension 1: Nature of the disease (5.3\% of variance) & 0.60 \\
The symptoms of MERS are fever with/without chilling, cough, and dyspnea & 0.57 \\
Recommended diagnostic approach in human is sampling of upper and & \\
lower airways secretions and PCR (polymerase chain reaction) examination & 0.54 \\
People infected with MERS-CoV typically travelled to countries near the & \\
Arabian Peninsula & 0.70 \\
Some types of fruit-eating bats are the main sourse of the disease in wildlife & 0.46 \\
The causative agent of MERS-CoV is coronavirus & 0.41 \\
MERS-CoV can be eliminated with 70\% alcohol & 0.47 \\
MERS-CoV can be prevented with the injection of a vaccine (Reverse-scored) & 0.59 \\
The incubation period of MERS is 2-14 days & 0.42 \\
The coronavirus can survive for 48 h in the environment &
\end{tabular}

Dimension 2: Transmission of disease (4.63\% of variance)

MERS-CoV is transmitted through direct contact with respiratory tract secretions

The disease can be transmitted through direct contact with contaminated camel's secretions, including urine, saliva, respiratory secretions, and blood

The disease can be transmitted through the consumption of raw products and raw/half-baked meat of infected camels

MERS-CoV is transmissible through haemodialysis (Reverse-scored)

Camels are one of the sources of transmission of MERS-CoV to human

MERS-CoV is probably transmissible from infected deceased patients

0.60

.57

.54

0.70

0.46

0.41

0.47

.59

0.42 cases of MERS-CoV infection, including physicians and nurses, should be limited and certain.

Exposed people with symptoms of fever, cough and diarrhoea should have sputum samples taken and PCR testing 


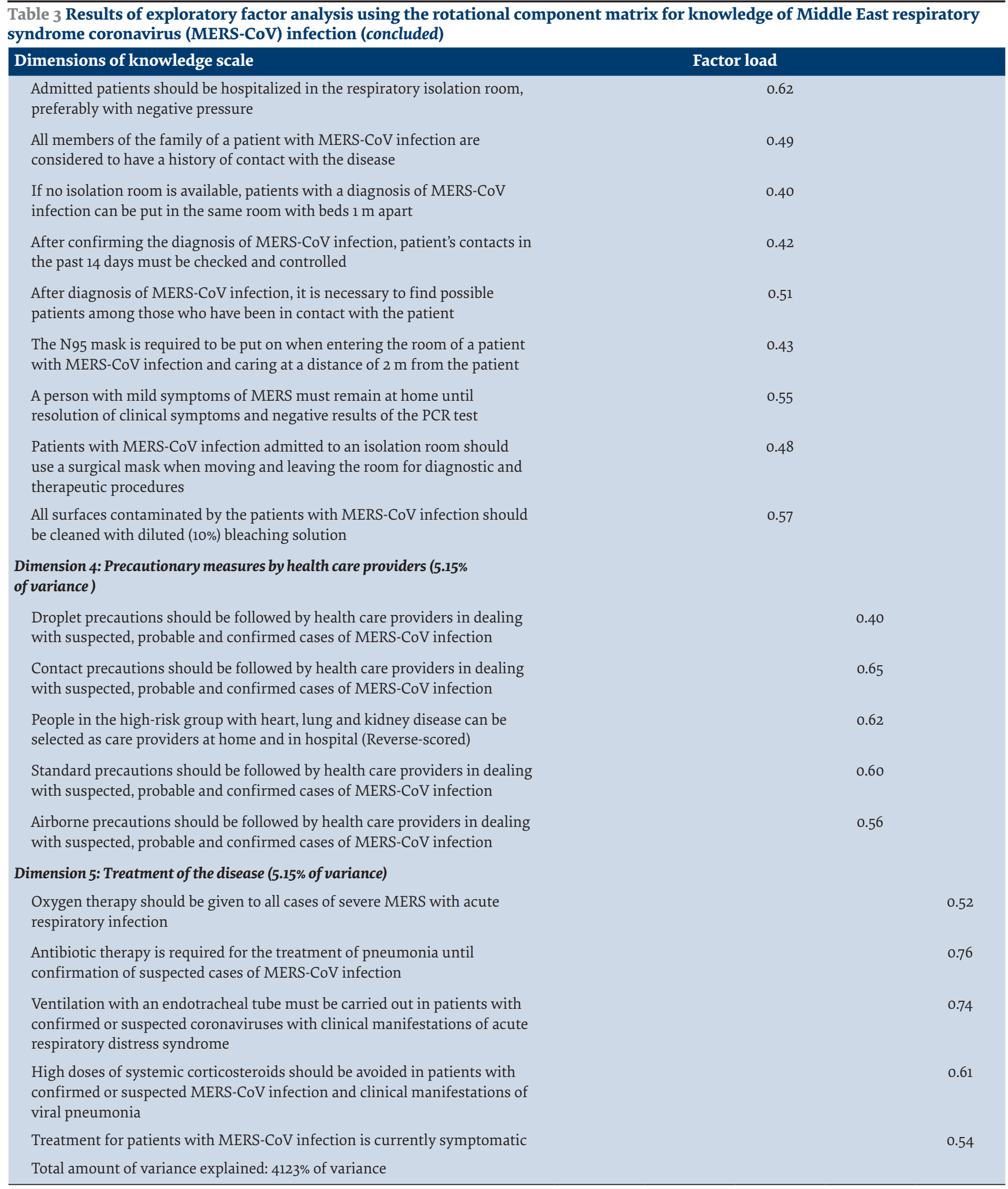

The correlation matrix in Table 4 shows significant correlations between total knowledge scores and total attitude scores $(P<0.001)$, beliefs about the prevention of MERS-CoV $(P<0.001)$ and the fears and threats of MERS$\operatorname{CoV}(P=0.019)$.

\section{Reliability}

The total internal consistency of the knowledge scale, assessed using Kuder-Richardson-21, was 0.94; its five dimensions Kuder-Richardson-21 ranged from 0.72 to 


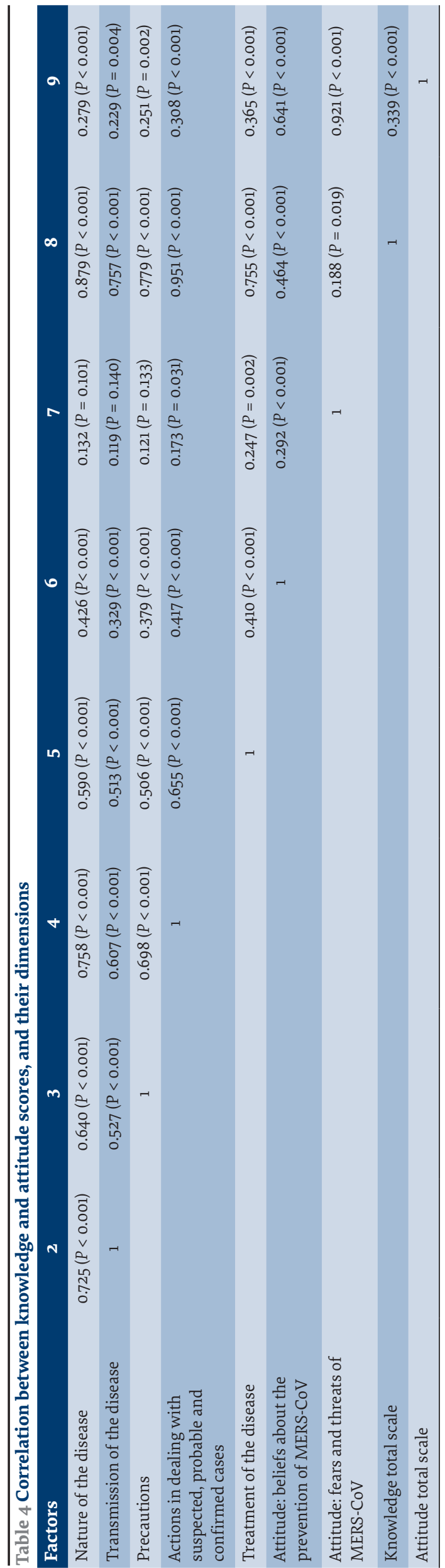

0.93. The internal consistency of the attitude scale was evaluated using the Cronbach alpha which gave values of $0.81,0.73$ and 0.82 for the dimensions of fears and threats of MERS-CoV, beliefs about the prevention of MERS-CoV, and for the entire scale respectively. When the questionnaire was assessed again after a two-week interval in the same sample of nurses, the value of the intraclass correlation coefficient for the entire knowledge scale was 0.91 and ranged from $0.76-0.88$ for its dimensions. Intraclass correlation coefficient values for the two dimensions of attitude were 0.85 for beliefs about the prevention of MERS-CoV and 0.89 for fears and threats of MERS-CoV, and 0.89 for the entire scale (Table 5).

\section{Scoring of the instrument}

Our final MERS-CoV instrument is composed of both knowledge and attitude scales. The knowledge scale includes five domains and 46 items in a triple-choice response scale (true, false and don't know) including: actions to deal with suspected, probable and confirmed cases ( 20 items), nature of the disease ( 9 items), precautionary measures by health care providers (5 items), treatment of the disease (5 items) and transmission of the disease ( 5 items). True answers scored 1 point and others scored o. A high score on the knowledge scale represents a high level of knowledge about MERS disease. The principle for scoring these scales is the same in all cases: (i) Estimate the sum of the items that contribute to the subscale - this is the raw score and (ii) Use a linear transformation to standardize the raw score so that scores range from o to 100 - a higher score represents a higher level of knowledge. The linear transformation score is derived as follows: linear transformation score $=($ raw score - minimum total score $) /($ maximum total score - minimum total score) $\times 100$. For example, in the subscale of actions to deal with suspected, probable and confirmed cases, the range of scores is 0 to 20 and the linear transformation score is equal to (raw score - 0 )/ $(20-0) \times 100$.

The attitude scale includes two domains, one with 11 items (fears and threats of MERS-CoV) and one with five (beliefs about the prevention of MERS-CoV) which are rated on a 5-point Likert response scale. Therefore, scores in the two subscales range from 11 to 55 , and 5 to 25 respectively. For example, in the first subscale of attitude, the linear transformation score is (raw score - 11)/(55 - 11) $\times 100$.

\section{Discussion}

We aimed to design and psychometrically evaluate an instrument and to assess nurses' knowledge of and attitude to MERS-CoV. Acceptable S-CVI/Ave values of 0.80 and 0.91 were obtained for the knowledge and attitude scales respectively $(21,23)$.

In the exploratory factor analysis of the knowledge and attitude scales, the Kaiser-Meyer-Olkin sampling adequacy indexes (0.864 and 0.758 respectively) and Bartlett's test $(P<0.001)$ indicated that implementation of factor analysis was justifiable based on the correlation 


\begin{tabular}{|c|c|c|c|}
\hline Scale & Number of items & Cronbach alpha & $\begin{array}{l}\text { Intraclass correlation } \\
\text { coefficient }\end{array}$ \\
\hline \multicolumn{4}{|l|}{ Attitude scale on MERS-CoV } \\
\hline Dimension 1: fears and threats of MERS-CoV & 11 & 0.81 & 0.89 \\
\hline Dimension 2: beliefs about the prevention of MERS-CoV & 5 & 0.73 & 0.85 \\
\hline Total & 16 & 0.82 & 0.89 \\
\hline Knowledge scale on MERS & Number of items & Kuder-Richardson-21 & $\begin{array}{l}\text { Intraclass correlation } \\
\text { coefficient }\end{array}$ \\
\hline Dimension 1: nature of the disease & 9 & 0.75 & 0.76 \\
\hline Dimension 2: transmission of the disease & 7 & 0.82 & 0.87 \\
\hline $\begin{array}{l}\text { Dimension 3: actions in dealing with suspected, probable and } \\
\text { confirmed cases }\end{array}$ & 20 & 0.93 & 0.85 \\
\hline Dimension 4: precautionary measures by health care providers & 5 & 0.72 & 0.88 \\
\hline Dimension 5: treatment of the disease & 5 & 0.81 & 0.79 \\
\hline Total & 46 & 0.94 & 0.91 \\
\hline
\end{tabular}

MERS: Middle East respiratory syndrome.

matrix obtained in the sample. A Kaiser-Meyer-Olkin level greater than 0.5 allows factor analysis (24).

The internal consistency of the knowledge scale assessed by the Kuder-Richardson-21 formula equalled to 0.94 for the total knowledge scale and $0.72-0.93$ for its dimensions. Cronbach alpha values of 0.73 and 0.81 were obtained for the dimensions of the attitude scale; values equal to or higher than 0.7 are acceptable and indicative of internal consistency of a scale (25). The intraclass correlation coefficient for the entire knowledge scale was 0.91 and that for the attitudes scale was 0.89; values equal to or more than 0.4 are acceptable (26), indicating that the questionnaires developed in our study was stable and reliable.

Following exploratory factor analysis, the knowledge scale items were categorized in five dimensions. The dimension that explained the greatest score variance in the knowledge scale $(18.45 \%)$ was actions in dealing with suspected, probable and confirmed cases. This dimension addresses measures on infection control, isolation, disinfection of surfaces, and actions in dealing with suspected, probable and confirmed cases (27). Nature of the disease explained $5.30 \%$ of the variance; this dimension focuses on the causative agent, disease reservoirs, diagnosis path, incubation period and the disease symptoms $(28,29)$. Precautionary actions by health care providers explained $5.15 \%$ of the score variance; this dimension emphasizes standard precautions, airborne and contact precautions, and high-risk groups (30). Treatment of the disease explained $5.15 \%$ of the score variance; this dimension concentrates on disease treatment approaches (30). Finally, disease transmission explained $4.63 \%$ of the variance; this dimension refers to the ways the disease is transmitted from animals to humans and/or from infected individuals to others $(8,31,32)$.

Attitude items were categorized into two dimensions (fears and threats of MERS-CoV) which explained 27.72\% of the variance, and beliefs about prevention of MERS$\mathrm{CoV}$ which explained $18.0 \%$ of the variance. The items of our scale on fears and threats of the disease are not consistent with those of the Korean study (14). This can be explained by the fact that the researchers developed the questionnaire based on one that assessed the public fear of severe acute respiratory syndrome.

The findings of our study are in line with a study in Saudi Arabia in 2014 with regard to knowledge questions (nature, etiology, symptoms, consequences, transmission, prevention and treatment). However, no measures were included in the Saudi Arabian questionnaire dealing with suspected, probable and confirmed cases, and precautions (10). All items in our questionnaire are also consistent with those used in a 2015 study in Saudi Arabia on the knowledge, attitude and practice of health care providers, although some of their questions had more than one answer (13). Moreover, three dimensions of our knowledge scale (nature, and treatment and prevention of the disease) agree with that of a Chinese study in 2015 that investigated MERS and knowledge, attitudes and practices of medical students related to MERS (33).

To the best of our knowledge, our study is one of the most rigorous studies to develop a reliable and valid instrument for assessing the knowledge and attitude of nurses in the front line of health care provision for people with MERS-CoV infection (34). We used face and content validity (quantitative and qualitative) methods, construct validity using exploratory factor analysis, and scale reliability using two methods of internal consistency and stability. Another significant feature of our study is using CDC and WHO guidelines on MERS as well as those of the Iranian Centre for Communicable Diseases. In addition, relevant scientific literature was reviewed to determine the content domains of MERS and generate items for the knowledge and attitude scales. 
Considering the use of extensive literature review and expert opinion for designing this scale and the evidence of the validity and reliability of our MERSCoV knowledge and attitude scale, we recommend its use to assess the knowledge and attitudes of nurses and hospital managers before and after training courses on the disease and in other research.

A limitation of this study was that it was only conducted among nurses and in two hospitals affiliated to Tabriz University of Medical Sciences. Nonetheless, the reliability of the scale can be examined for other health care service providers (e.g. physicians, paramedics, and medical, paramedical and nursing students), and in different locations in the Islamic Republic of Iran or even other parts of the world.

Funding: Tabriz University of Medical Sciences, Islamic Republic of Iran (IR.TBZMED.REC.1395.1065).

Competing interest: None declared.

\section{Mise au point d'un questionnaire pour évaluer les connaissances et les attitudes des personnels infirmiers iraniens vis-à-vis du Syndrome respiratoire du Moyen-Orient \\ Résumé}

Contexte: Avec l'émergence du Syndrome respiratoire du Moyen-Orient (MERS), une attention croissante a été accordée à la préparation en matière de soins de santé, nécessitant des outils valables pour évaluer les connaissances et les attitudes vis-à-vis de cette maladie chez les agents de santé, tels que les personnels infirmiers.

Objectifs : La présente étude visait à mettre au point et à évaluer un questionnaire sur les connaissances et attitudes vis-à-vis du coronavirus du Syndrome respiratoire du Moyen-Orient (MERS-CoV) à l'attention des personnels infirmiers iraniens.

Méthodes : Un questionnaire a été préparé sur la base des directives internationales et nationales et d'une revue de la littérature. Dix membres du personnel infirmier ont été recrutés pour évaluer la validité apparente et 11 experts ont examiné l'instrument pour déterminer le ratio et l'indice de validité du contenu. Une analyse factorielle exploratoire a ensuite été réalisée sur un échantillon aléatoire de 155 personnels infirmiers dans la ville de Tabriz, en République islamique d'Iran.

Résultats : Après avoir déterminé la validité apparente et du contenu, 78 items (61 pour les connaissances et 17 pour les attitudes) ont été retenus dans la version finale du questionnaire. L'échelle des connaissances avait un indice de validité du contenu moyen de 0,80 et l'échelle d'attitudes une valeur de 0,91. À l'analyse factorielle exploratoire, cinq dimensions ayant des valeurs propres supérieures à 1 et un coefficient de saturation supérieur ou égal à 0,4 ont été extraites pour l'échelle des connaissances (46 items) et deux pour l'échelle d'attitudes (16 items). Le coefficient de Kuder-Richardson formule 21 et le coefficient de corrélation intra - classe pour l'échelle des connaissances étaient respectivement de 0,94 et 0,91 . Dans l'échelle d'attitudes, le coefficient alpha de Cronbach et le coefficient de corrélation intra-classe étaient respectivement de 0,82 et 0,89 .

Conclusions : L'échelle mise au point dans cette étude est fiable et stable. Elle constitue également un instrument approprié pour évaluer les connaissances et les attitudes des personnels infirmiers au sujet du MERS-CoV.

$$
\begin{aligned}
& \text { إعداد استبيان لتقييم معلومات واتجاهات الممرضين الإيرانيين تجاه متلازمة الشرق الأوسط التنفسية } \\
& \text { معصو مة عبد الله، أكرم قهر مانيان، شهال شهبازي، فرشيد رضائي، بهروز نقيلي، محمد أصغري جعفر أبادي }
\end{aligned}
$$

$$
\begin{aligned}
& \text { الخلفية: حظيت استعدادات الرعاية الصحية باهتمام متزايد مع ظهور متلازمة الشرق الأوسط التنفسية، مما يتطلب أدوات صالحة لتقييم معلو مات }
\end{aligned}
$$

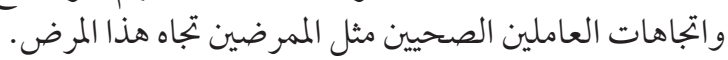

$$
\begin{aligned}
& \text { الأهداف: هدفت هذه الدراسة إلى إعداد استيان لتقييم المعلومات والاتجاهات بشأن فيروس كورونا المسبب لمتلازمة الشرق الأوسط التنفسية لدى المين } \\
& \text { الممرضين الإيرانين. } \\
& \text { طرق البحث: أعد استبيان يستند إلى المبادئ التوجيهية الدولية والوطنية وإلى مراجعة المؤلفات. وجرى تعبين عشرة المئن من طاقم التمريض لتقييم }
\end{aligned}
$$

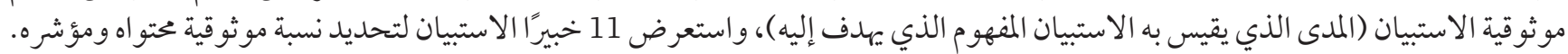

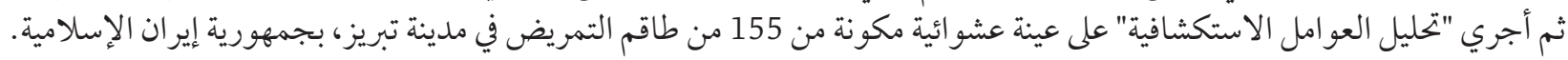

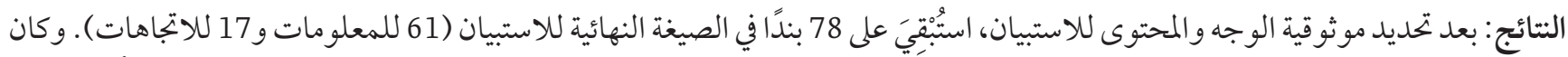

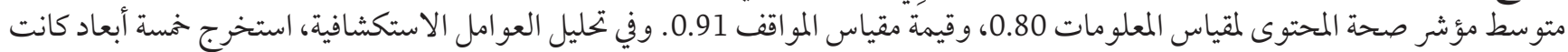

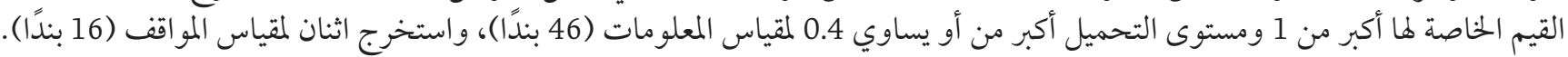




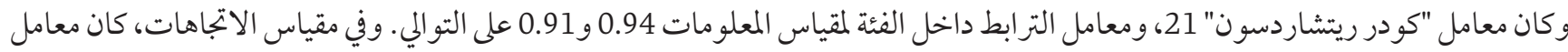

$$
\begin{aligned}
& \text { "كرونباخ ألفا"، ومعامل الترابط داخل الفئة } 0.82 \text { و و } 0.89 \text { على التو الي. }
\end{aligned}
$$

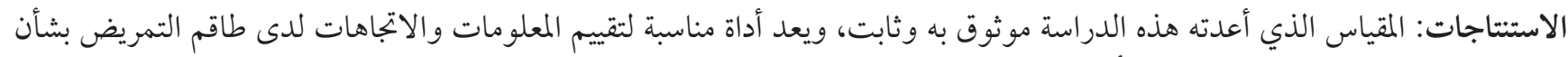

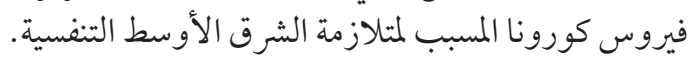

\section{References}

1. Middle East respiratory syndrome coronavirus (MERS-CoV). Fact sheet. Geneva: World Health Organization; 2019 (https://www. who.int/news-room/fact-sheets/detail/middle-east-respiratory-syndrome-coronavirus-(mers-cov), accessed 27 June 2019).

2. Middle East respiratory syndrome coronavirus (MERS-CoV) - Saudi Arabia and Qatar. Emergencies preparedness, response, World Health Organization; 2017 [webpage] (http://www.who.int/csr/don/27-april-2017-mers-saudi-arabia-and-qatar/en/, accessed 27 June 2019).

3. Middle East Respiratory Syndrome (MERS). Centers for Disease Control and Prevention; 2017(https://www.cdc.gov/coronavirus/ mers/, accessed 27 June 2019).

4. Yavarian J, Rezaei F, Shadab A, Soroush M, Gooya MM, Azad TM. Cluster of Middle East respiratory syndrome coronavirus infections in Iran, 2014. Emerg Infect Dis. 2015;21(2):362-4. https://doi.org/10.10.3201/eid2102.141405

5. Middle East Respiratory Syndrome coronavirus (MERS-CoV) - Iran. World Health Organization, Emergencies preparedness response, Disease outbreak news, 8 May 2015 (http://www.who.int/csr/don/8-may-2015-mers-iran/en/, accessed 22 June 2019).

6. Saad M, Omrani AS, Baig K, Bahloul A, Elzein F, Matin MA, et al. Clinical aspects and outcomes of 70 patients with Middle East respiratory syndrome coronavirus infection: a single-center experience in Saudi Arabia. Int J Infect Dis. 2014;29:301-6. https:// doi.org/10.10.1016/j.ijid.2014.09.003

7. Nour MO, Babalghith AO, Natto HA, Alawneh SM, Elamin FO. Raising awareness of health care providers about MERSCoV infection in public hospitals in Mecca, Saudi Arabia: East Mediterr Health J. 2017:23(8):534-42.

8. Cowling BJ, Park M, Fang VJ, Wu P, Leung GM, Wu JT. Preliminary epidemiologic assessment of MERS-CoV outbreak in South Korea, May-June 2015. Euro Surveill. 2015;20(25):7-13. https://doi.org/10.10.2807/1560-7917.es2015.20.25.21163

9. Oboho IK, Tomczyk SM, Al-Asmari AM, Banjar AA, Al-Mugti H, Aloraini MS, et al. 2014 MERS-CoV outbreak in Jeddah-a link to health care facilities. N Engl J Med. 2015;372(9):846-54. https://doi.org/10.10.1056/NEJMoa1408636

10. Khan MU, Shah S, Ahmad A, Fatokun O. Knowledge and attitude of healthcare workers about middle east respiratory syndrome in multispecialty hospitals of Qassim, Saudi Arabia. BMC Public Health. 2014;14:1281. https://doi.org/10.10.1186/1471-2458-14-1281

11. Pavli A, Tsiodras S, Maltezou HC. Middle East respiratory syndrome coronavirus (MERS-CoV): prevention in travelers. Travel Med Infect Dis. 2014;12(6 Pt A):602-8. https://doi.org/10.10.1016/j.tmaid.2014.10.006.

12. Khalid I, Khalid TJ, Qabajah MR, Barnard AG, Qushmaq IA. Healthcare workers emotions, perceived stressors and coping strategies during MERS-CoV outbreak. Clin Med Res. 2016.1303. https://doi.org/10.10.3121/cmr.2016.1303

13. Nour MO, Babilghith AO, Natto HA, Al-Amin FO, Alawneh SM. Knowledge, attitude and practices of healthcare providers towards MERS-CoV infection at Makkah hospitals, KSA. Int Res J Med Med Sci. 2015;3(4):103-12.

14. Kim JS, Choi JS. Middle East respiratory syndrome-related knowledge, preventive behaviours and risk perception among nursing students during outbreak. J Clin Nurs. 2016;25(17-18):2542-9. https://doi.org/10.10.1111/jocn.13295

15. Sahin MK, Aker S, Tuncel EK. Knowledge, attitudes and practices concerning Middle East respiratory syndrome among Umrah and Hajj pilgrims in Samsun, Turkey, 2015. Euro Surveill. 2015;20(38). http://dx.doi.org/10.2807/1560-7917.ES.2015.20.38.30023

16. Sultana A, Awais S, Mahmood F. Knowledge about MERS (Middle Eastern respiratory syndrome) among doctors in holy family hospital, Rawalpindi. J Islam Int Med Coll. 2016;11(2):71-5.

17. Alkot M, Albouq MA, Shakuri MA, Subahi MS. Knowledge, attitude, and practice toward MERS-CoV among primary healthcare workers in Makkah Al-Mukarramah: an intervention study. Int J Med Sci Public Health. 2016;5(5):952-9. doi:10.5455/ijmsph.2016.10022016362

18. Zamanzadeh V, Ghahramanian A, Rassouli M, Abbaszadeh A, Alavi-Majd H, Nikanfar A-R. Design and implementation content validity study: development of an instrument for measuring patient-centered communication. J Caring Sci. 2015;4(2):165-78. https://doi.org/10.10.15171/jcs.2015.017

19. Lawshe CH. A quantitative approach to content validity. Pers Psychy. 1975;28(4):56375. https://doi.org/10.10.1111/j.1744-6570.1975. tbo1393.x

20. Waltz CF, Bausell BR. Nursing research: design statistics and computer analysis: Philadelphia: FA Davis Co.; 1981.

21. Ghiasvand A. Use of statistics and SPSS software for data analyses. 1st edition. Tehran: Louie Publication; 2009.

22. Michael F, Verne B. Psychometrics: an introduction. London: SAGE Publication; 2014.

23. Polit DF, Beck CT, Owen SV. Is the CVI an acceptable indicator of content validity? Appraisal and recommendations. Res Nurs Health. 2007;30(4):459-67. https://doi.org/10.10.1002/nur.20199 
24. Williams B, Onsman A, Brown T. Exploratory factor analysis: A five-step guide for novices. Australasian J Paramedicine. 2010;8(3).

25. Clark LA, Watson D. Constructing validity: Basic issues in objective scale development. Psychol Assess. 1995;7(3):309-19.

26. Terwee CB, Bot SD, de Boer MR, van der Windt DA, Knol DL, Dekker J, et al. Quality criteria were proposed for measurement properties of health status questionnaires. J Clin Epidemiol. 2007;60(1):34-42. https://doi.org/10.10.1016/j.jclinepi.2006.03.012

27. Madani TA, Althaqafi AO, Alraddadi BM. Infection prevention and control guidelines for patients with Middle East respiratory syndrome coronavirus (MERS-CoV) infection. Saudi Med J. 2014;35(8):897-913.

28. Badawi A, Ryoo SG. Prevalence of comorbidities in the Middle East respiratory syndrome coronavirus (MERS-CoV): a systematic review and meta-analysis. Int J Infect Dis. 2016;49:129-33. https://doi.org/10.10.1016/j.ijid.2016.06.015

29. Munster VJ, Adney DR, Van Doremalen N, Brown VR, Miazgowicz KL, Milne-Price S, et al. Replication and shedding of MERSCoV in Jamaican fruit bats (Artibeus jamaicensis). Sci Rep. 2016;6:21878. https://doi.org/10.10.1038/srep21878.

30. Ministry of Health and Medical Education. [Middle East respiratory syndrome coronavirus (MERS $\triangle \mathrm{CoV}$ ). Surveillance guideline (version April 2014)]. (http://treatment.tbzmed.ac.ir/uploads/14/CMS/user/file/2/corona_guidelines_final.pdf, accessed 8 Juky 1019) [in Farsi].

31. Azhar EI, El-Kafrawy SA, Farraj SA, Hassan AM, Al-Saeed MS, Hashem AM, et al. Evidence for camel-to-human transmission of MERS coronavirus. N Engl J Med. 2014;370(26):2499-505. https://doi.org/10.10.1056/NEJMoa1401505

32. van Doremalen N. Stability of Middle East respiratory syndrome coronavirus in milk. 2014. Emerg Infect Dis. 2014:20(7):1263-4. https://doi.org/10.10.3201/eid2007.140500

33. Liu M, Jiang C, Donovan C, Wen Y, Sun W. Middle East respiratory syndrome and medical students: letter from China. Int J Environ Res Public Health. 2015;12(10):13289-94. doi:10.3390/ijerph121013289

34. Simonds A, Sokol D. Lives on the line? Ethics and practicalities of duty of care in pandemics and disasters. Eur Respir J. 2009;34(2):303-9. https://doi.org/10.10.1183/09031936.00041609 